\title{
Integrating Waste Characterisation into Landform Design for Low-Risk and Low-Cost Mine Closure
}

\author{
D.A. Jasper Landform Solutions, Australia
}

M.F. Braimbridge Outback Ecology Services, Australia

H.W.B Lacy Landform Solutions, Australia

M. Russell Landform Solutions, Australia

\section{INTRODUCTION}

Waste landforms represent a substantial component of the challenge of achieving successful mine closure. Issues may arise from surface and subsurface instability, inadequate vegetative establishment and growth, and release of chemically-hostile materials. Characterising waste materials before constructing the landform, is a key step to maximise the likelihood that the final landform will satisfy stakeholder expectations, and facilitate the construction of a physically and chemically stable and sustainable landform. Additionally, an improved level of planning will enable an economically optimum landform to be constructed.

Given the diversity of issues that may arise from the deposition of mine wastes at the surface, initial characterisation needs to address a suite of inter-related physical, chemical and biological properties, to identify optimal waste placement parameters. While recommendations for waste placement can be developed, these need to be integrated with optimisation and design of the waste dumping schedules. This is now being tackled through the application of planning and optimisation software, that allows detailed scheduling of waste dumping, to achieve the best environmental outcome, at least cost.

\subsection{Current Practice and Possible Outcomes of Landform Construction and Rehabilitation}

Current practices in mine planning and mine operations are rudimentary with little cognisance being given to optimising the economic cost of developing the dump. Mining focus continues to be on the pit with little time given to the waste landform. There are some examples of well-planned landforms, which have effectively encapsulated mineralised waste, are not eroding, and have appropriate vegetation. Such landforms have generally been constructed by larger companies, using numerous disciplines to effectively characterise materials and plan the associated construction. There are many more examples however, where, although done with the best intentions and using the accepted practice of the day, at least one aspect has been poorly planned. Consequently, such landforms, where the physical and chemical nature of the materials has been overlooked or not incorporated into the landform, are unlikely to be environmentally low-risk or to meet requirements for bond release (Jones, 2004).

\subsection{Integrating Landform Planning with Mine Planning - The Realities on Mine Sites}

Mining waste landforms are common features for the vast majority of open pit mining operations. However when looked at objectively there are aspects of landform planning which directly conflict with achieving an economically optimal and environmentally low-risk outcome. These include:

- Tools: There has been a lack of recognition that waste landforms represent an opportunity for significant cost savings. As a result, engineering tools have not been developed for their efficient design. Some attempts have been made to "invert" pit planning tools but these have not gained substantial acceptance and in some cases have been directly detrimental to good economic and environmental outcomes. Without the tools being available the modern mine planning engineer is unlikely to appropriately tackle this task. 
- Training: Historically, there has been little emphasis on optimising the design of mining waste landforms. Open pit optimisation had become "main stream" over the last quarter of a century with methods (and software) becoming well established. Since the mining industry has yet to recognise the full benefits to planning the waste landform, mine planning methodologies and hence training does generally not cover this field.

- Time: Mining engineers are too busy. The simple fact is that without the correct re-allocation of time by site management, virtually all mining engineering time will continue to focus in the pit, in what is called the "value chain". Whilst this is the correct allocation for the majority of time there remains significant value to be added by appropriate landform design work. It needs to be appreciated that landforms can form part of this value chain.

- No effective industry standards: While attempts have been made to provide guidelines concerning the construction of stable waste landforms (eg. DoIR, 1996), the reality is that these have only had limited success. Such guidelines can result in a 'default design' approach that is not necessarily appropriate from the standpoint of long and even short term stability (Jones, 2004). However, industry may be reluctant to stray far from these guidelines for the fear of the consequences of potential failure. Mediocrity can be safer.

- Moving target for landform design: Building a waste landform is not like baking a pre-packaged cake mix. The ingredients for the landform, the waste materials, are often poorly understood both in terms of behaviour (physical and chemical properties, etc) (Jasper and Braimbridge, 2006) and their individual volumes. This is completely understandable as the main geological focus is almost exclusively on the ore intersections. Engineers do not operate well with this level of uncertainty.

Additionally there are several features of the landform that should encourage more rigour, analysis and evaluation if low cost and low risk designs are to be generated.

- Strip ratios: The majority of mines have strip ratios greater than one, and as such, there is value in considering them as waste mines, with ore as a by-product (Jones, 2004). The recent substantial increase in metal prices will have the knock-on effect of making even higher strip ratios economically viable.

- Truck haulage: The geometry of the pits and the surrounding topography dictate that substantial trucking time is actually spent directly on the waste landform. While this may vary, both overall and throughout the life of the mine, the truck fleet may spend up to a half of its operating hours on the waste landform.

- Mine closure too far distant: The general lack of engineering time available, combined with the dearth of tools and methodologies, means that there is inadequate engineering consideration for the final landform. It seems that the continual focus on short term profit has a prejudicial effect of discounting the quality of long term planning. An additional deterrent to careful long-term planning is the operating environment of constant change, which is typical of most sites.

- No guaranteed results: Mine operators and planners like certainty. Yet the results of rehabilitation can not be guaranteed without substantial trial work that by its nature requires several years to assess.

Based upon our experience on waste landforms the current methodologies have two significant economic impacts.

- Higher construction cost: Anecdotally, experience shows that mines are spending $5-15 \mathrm{c}$ per bank cubic metre $(\mathrm{bcm})$ more on creating the waste landform than is necessary. Whilst this might not seem significant it will normally represent multi-million dollars at most mines and can be up to 5\% of the total load and haul cost.

- Higher closure cost: Whilst it is not possible to define the closure cost, and many operations still do not budget for this, it is clear that "getting it right first time" is, by far, the cheapest option. As a specific example, recent remedial closure works on waste landforms at the Woodcutters Mine in the Northern Territory incurred costs of more than $\$ 330,000 /$ ha (May, 2004). More generally, industry 
estimates suggest that remedial costs at closure can be up to five times more than the costs of appropriate construction through proper planning (Dowd, 2005).

\section{DEFINING KEY MATERIAL PROPERTIES AND PLACEMENT RECOMMENDATIONS}

\subsection{Key Properties of Mine Wastes}

Given the diversity of issues that may arise from placing mine wastes in constructed landforms, initial characterisation needs to address a suite of physical and chemical parameters (Table 1). Many of these properties are inter-related, with many site specific issues arising from dynamic relationships between individual soil properties.

Important physical properties include particle size distribution (soil texture), soil structural stability (slaking and dispersion), hard-setting and armouring tendencies. Numerous studies have investigated the influence of such properties on the capacity of the material to resist erosional forces (e.g. Murphy et al., 1993; Shainberg et al., 1992; Sheridan et al., 2000), accept rainfall infiltration (e.g. Mamedov et al., 2001), and to store water that is subsequently available for plant growth (e.g. Roberts et al., 1988). Water retention is also critical to minimise deeper drainage into potentially hostile wastes, such as those with acid-forming potential (O'Kane et al., 1999). The chemical properties of wastes may relate to critical environmental issues such as the potential for acid formation, or release of metals (e.g. Lottermoser et al., 1999), through to key factors affecting plant growth (soil $\mathrm{pH}$, salinity) and then more subtle measures such as nutrient levels.

The properties of soils and waste materials need to be defined prior to landform construction to ensure that each material is suitable both for its final placement in the landform, and for the target plant community to be re-established. While vegetation communities are the visible outcome of mine rehabilitation, and thus are the logical focus of rehabilitation planning, successfully establishing specific communities can only be achieved if an appropriate soil environment has been created. In undisturbed and rehabilitated ecosystems, the make-up of plant communities is strongly linked to soil type and landscape position (Merrill et al., 1998).

Mine waste characteristics fall into two groups - intrinsic and dynamic. Intrinsic characteristics reflect the starting condition of the waste, and are determined by the mineralogy, chemistry and physical properties of the material. These intrinsic properties, such as soil texture, are generally not able to be amended, yet they have a very strong impact on rainfall infiltration, erosion and ultimately, plant productivity. Some chemical and physical and biological properties of soils are more dynamic, potentially changing over time, such as soil $\mathrm{pH}$ or electrical conductivity. However, the rate and direction of change will largely be driven by physical and chemical processes such as infiltration, drainage and weathering. The end products of waste material weathering should be an important component to waste characterisation at the outset so landform planning can accommodate these properties. The development of simple, site specific tests, to ensure that all waste can be classified in the field, is often an important aspect of material characterisation and the associated allocation of materials to the most appropriate part of the landform. 

potential for environmental impact (adapted from Jasper and Braimbridge, 2006)

\begin{tabular}{|c|c|}
\hline Physical & Chemical \\
\hline $\begin{array}{l}\text { - Particle size distribution (soil texture, \% } \\
\text { coarse material) } \\
\text { - Bulk density } \\
\text { - Soil structure } \\
\text { - Slaking and dispersion } \\
\text { - Soil strength (crust formation, hard-setting) } \\
\text { - Infiltration and hydraulic conductivity } \\
\text { - Water retention properties } \\
\text { - Erodibility }\end{array}$ & $\begin{array}{l}\text { - } \text { Soil } \mathrm{pH} \\
\text { - } \text { Salinity (electrical conductivity) } \\
\text { - } \text { Total and available nutrients } \\
\text { - } \text { Heavy metal availability } \\
\text { - } \text { Cation exchange capacity / Exchangeable Na } \\
\text { - } \text { Exchangeable Na } \\
\text { - Sulfides / Net Acid Generation } \\
\text { - Carbonates / Acid Neutralisation Capacity } \\
\text { - } \text { Mineralogy }\end{array}$ \\
\hline
\end{tabular}

\subsection{Practical Options for Placement on Landforms}

Ideally, the options for landform design, such as the area of the footprint, the slope of external batters, and the specific placement of each waste material, should be based around the properties of the materials available and the expected climatic regime (DITR, 2006). Properties that are particularly relevant are those which influence the likely resistance to erosion and ability to support target vegetation, and those which risk acid formation and metal release (Table 2).

Examples of specific waste identification and placement options include dispersive soils being placed away from the surface if possible, to avoid creating long-term issues of surface instability. Surface stability may also be enhanced by the application of suitable coarse material to 'armour' the surface of the constructed landform (e.g. Figueiredo and Poesen, 1998; Cerdà, 2001). Layers of coarse material forming a capillary break may be incorporated into reconstructed soil profiles, on saline waste materials such as tailings, to prevent the upward movements of salts to the surface soils. The encapsulation of potentially acid forming materials may require the construction of a store / release cover, constructed from suitable materials, capable of preventing the deep percolation of rainfall (Campbell, 2004). 
Table 2 A typical example of the diverse wastes found in open pit mining in the eastern goldfields of Western Australia, and of placement strategies based on waste characterisation

\begin{tabular}{|l|c|l|c|}
\hline Materials & $\begin{array}{c}\text { Amount } \\
\text { (\%) }\end{array}$ & \multicolumn{1}{|c|}{ Properties } & Placement \\
\hline Caprock & 14 & $\begin{array}{l}\text { High \% coarse fraction, structurally stable, } \\
\text { pH and EC suitable for native vegetation }\end{array}$ & Outer surfaces \\
\hline $\begin{array}{l}\text { Regolith } \\
\text { ('oxide') }\end{array}$ & 55 & $\begin{array}{l}\mathrm{pH} 7 \text { - 9, low EC, dispersive, higher erosion } \\
\text { risk }\end{array}$ & Sub-surface \\
\hline $\begin{array}{l}\text { Waste rock } \\
\text { - basalt }\end{array}$ & 10 & Non acid forming (NAF), structurally stable & Outer surfaces \\
\hline - mafic and felsic & 12 & Potentially acid forming (PAF) & Encapsulate \\
\hline - crystic / felsic & 2 & NAF, high \% coarse fraction, structurally stable & Outer surfaces \\
\hline - ultramafic & 5 & NAF & Internal \\
\hline Low-grade ore & 2 & Potentially acid forming (PAF) & $\begin{array}{c}\text { Discrete and } \\
\text { encapsulate }\end{array}$ \\
\hline
\end{tabular}

In practice, final design of a landform has more commonly been a compromise between constraints such as the area of land available, the timing of availability of the materials as determined by the mine schedule, and the cost of haulage. The challenge of working with these constraints and still achieving the best possible design outcome for the landform is most easily addressed early in the planning stages. It is well-established that it is far more cost-effective to design and construct landforms that will meet closure requirements during operations, than to superimpose these when mining has been completed (Dowd, 2005).

An important advantage in achieving landform design that has the best possible environmental values, is to link the design and construction as closely as possible to the mine plan. Examples have been reported of the application of cost-optimisation software, which allows detailed scheduling of waste dumping, to achieve the best environmental outcome, at least cost (Russell and Jasper, 2004).

\section{PLANNING LEAST-COST, LOW-RISK LANDFORMS}

Several steps are required to ensure that a low cost and low risk waste landform is developed. While this section expands on the Mine Planning requirements it is also worth noting that there are several other "drivers" to ensure that this consistently applies, these include:

- Recognition: There needs to be the recognition by management that proper planning of waste landforms does have value (economically and environmentally).

- The team: A multi disciplinary team needs to be involved. No single professional has all of the answers.

- A simple test: If materials are to be dumped separately then simple and clear tests need to be defined. These tests must be able to be undertaken in the mine under the most adverse conditions. Every truck load of waste rock needs to be correctly assigned if it is to have any chance of being correctly located in the landform. 
- The plan: A formal Dumping Plan needs to be drawn up so that all relevant people are aware of the required development, period by period.

- Formal risk assessment: The Dumping Plan needs to be rigorously reviewed and 'owned' by the operators. All parties must clearly understand the requirements for the landform construction and the consequence of deviating from the plan.

- Periodic review: The fact that the waste landform has been based on generally imperfect information means that periodic review of the planning and operation is essential. The question needs to be asked "will this dumping plan deliver the end point (result) that I anticipate / require?" If the answer to the review is no, then the plan needs to be appropriately modified to ensure that the required result is achieved.

\subsection{Optimising the Location and Footprint}

The economic optimisation of waste landforms can be very simply split into three cost components:

- Area costs: Those costs associated with the pre and post-mining activities on the land. This may include such activities as land acquisition, clearing and grubbing, topsoil removal and storage as well as rehabilitation, dozer profiling, topsoil/rock mulch placements, ripping and seeding, etc. It may also include the cost of servicing environmental bonds. These costs are generally expressed as a cost per hectare and may vary across the potential waste landform site.

- Variable haulage costs: These costs relate to placing the waste at a position in space. In doing this the horizontal and vertical haul components need to be fully included, based upon anticipated haulage routes. The costs are generally expressed as a cost per volume of waste.

- Fixed haulage costs: In addition to the variable haulage component there is also a fixed haulage cost that is related to non-trucking construction and maintenance of the landform as well as some fixed trucking costs. These costs are generally fixed for the entire landform but will vary if the key configurations (e.g. dump bench height, etc.) are modified.

Area costs and haulage costs are the main drivers to dumping economics. Additionally, there are other inputs including waste volumes, swell factors, slope configurations, material types and timings. There may also be special requirements for material placement to take into account (see 3.2 below).

When determining the strategic efficacy of certain dumping locations it is useful to also employ a series of physical constraints to dumping. These may include boundary shapes (e.g. lease and infrastructure boundaries, etc), levels and "jelly moulds" depending on the requirements. It is valuable to consider combinations of a series of fixed and potentially removable constraints, with the aim of objectively evaluating the implication of specific areas being accessible to dumping.

The end result is that an objective, economic assessment can be made on the benefits of allowing nominated dumping locations / configurations to be used, and so the strategic footprint of the dump can be defined.

\subsection{Incorporating Waste Placement Recommendation and Mining Schedule into the Landform Designs}

Determining the most economic and environmentally-appropriate footprint and overall landform shape can really be considered as only the beginning of the planning. There is also the need to ensure that it can be constructed efficiently and effectively, i.e. the landforms development must be scheduled.

Typically, many mines simply continue with the same dumping methodologies period after period without any consideration to the economic or environmental results. However, there can be many alternative drivers to scheduling the development of the waste landform. These include, but are not limited to:

- Best NPV: Lowest cost blocks dumped first.

- Rehabilitation driven: Accelerated rehabilitation by developing outer faces early. 
- Material requirements: Material placement that takes into account the physical and chemical characteristics of the waste.

- Equipment driven: Maximising truck utilisation by combining the in-pit haulage component with that on the waste landform to fully utilise the trucking fleet.

- Flexibility / Risk: In many cases the ultimate (and absolutely final) pit would not have been defined. Flexibility may therefore be required to cater for potentially larger or smaller volumes in the waste landform.

Each of the above approaches has specific advantages and disadvantages that should be fully understood. Also, it may be the case that it is not possible for all of the desired drivers to be mutually achieved. Compromise may be required in such cases.

For the landform to be effective there is a need to understand both the nature and the timing of the material that will be used in construction, however scheduling the placement of these materials can be complex when there is a diversity of material types (Table 2 and Figure 1). The nature of the material will determine the positional requirements within the landform (Section 2) and the timing will determine the practicality of achieving the final design. Without accurate scheduling, significant uncertainty exists and hence significant environment and economic risk. Integrating placement requirements with the mine production schedule, all within a framework of economic optimisation methodology, creates an opportunity for acceptable environmental outcomes at least cost. In the case illustrated in Figure 1, a logical dumping plan was developed to achieve a specific environmental outcome at the lowest cost.

\subsection{Evaluation of Alternative Waste Landform Strategies}

It is true to say that every waste landform is unique in terms of material types, volumes and location. As such there is no "one size fits all" applicable to the design of economically optimal and low risk landforms. Optimization methodologies can be particularly useful in evaluating alternative strategies for dumping. One such strategy recently evaluated is that of an Integrated Waste Landform (IWL), incorporating the disposal of tailings material within the waste landform (Figure 2). Integrated waste landforms can bring significant economic benefits of savings in both capital costs for perimeter bank construction and in operating costs, together with environmental benefits from progressive rehabilitation of external embankments of the tailings structure (Lane, 2004). The IWL concept also brings inherent benefits in long-term stability after closure, by storing potentially-erosive tailings, well within a waste landform. 


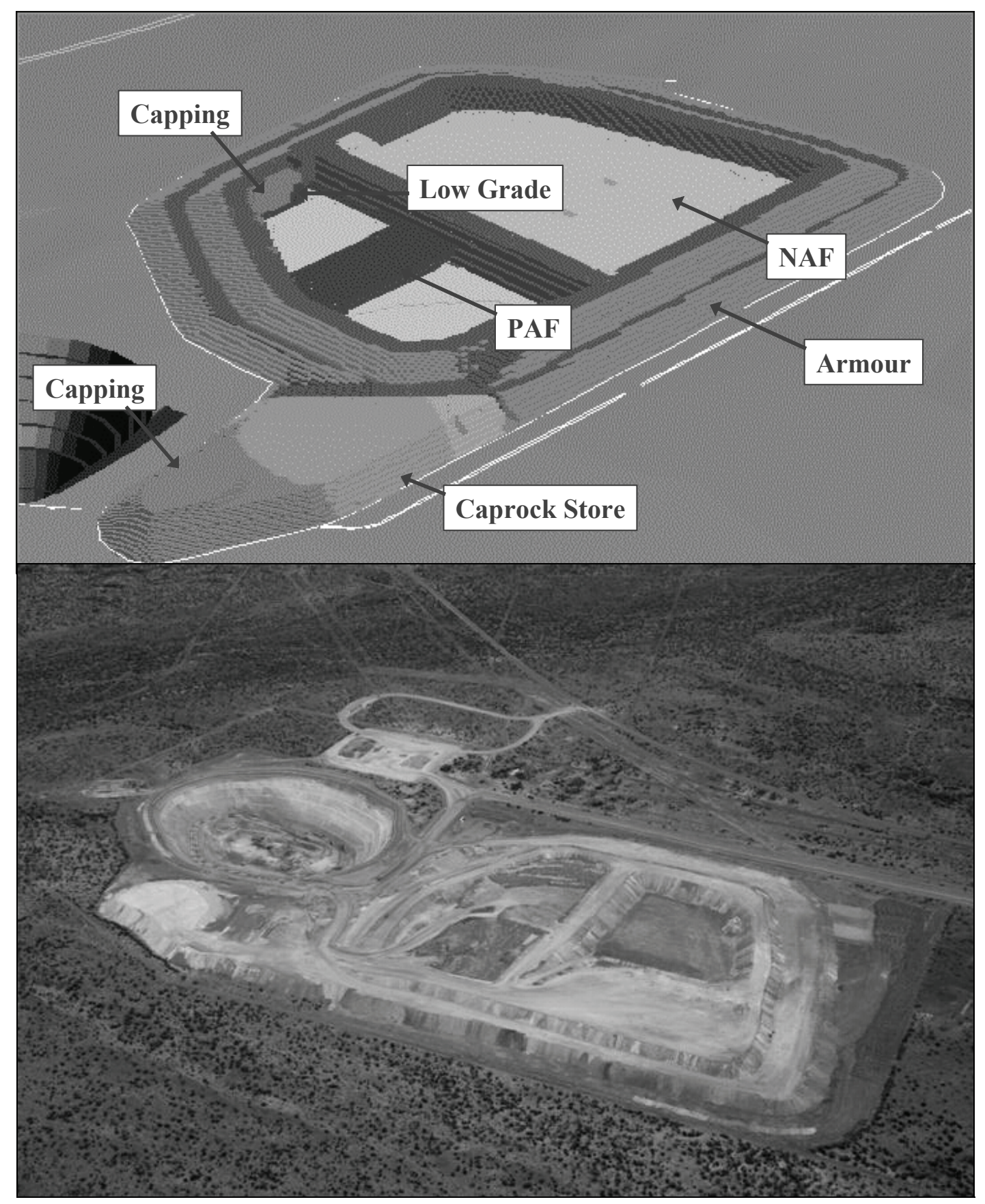

Figure 1 Example of landform scheduling involving seven waste materials requiring specific placement consideration in planning and construction 


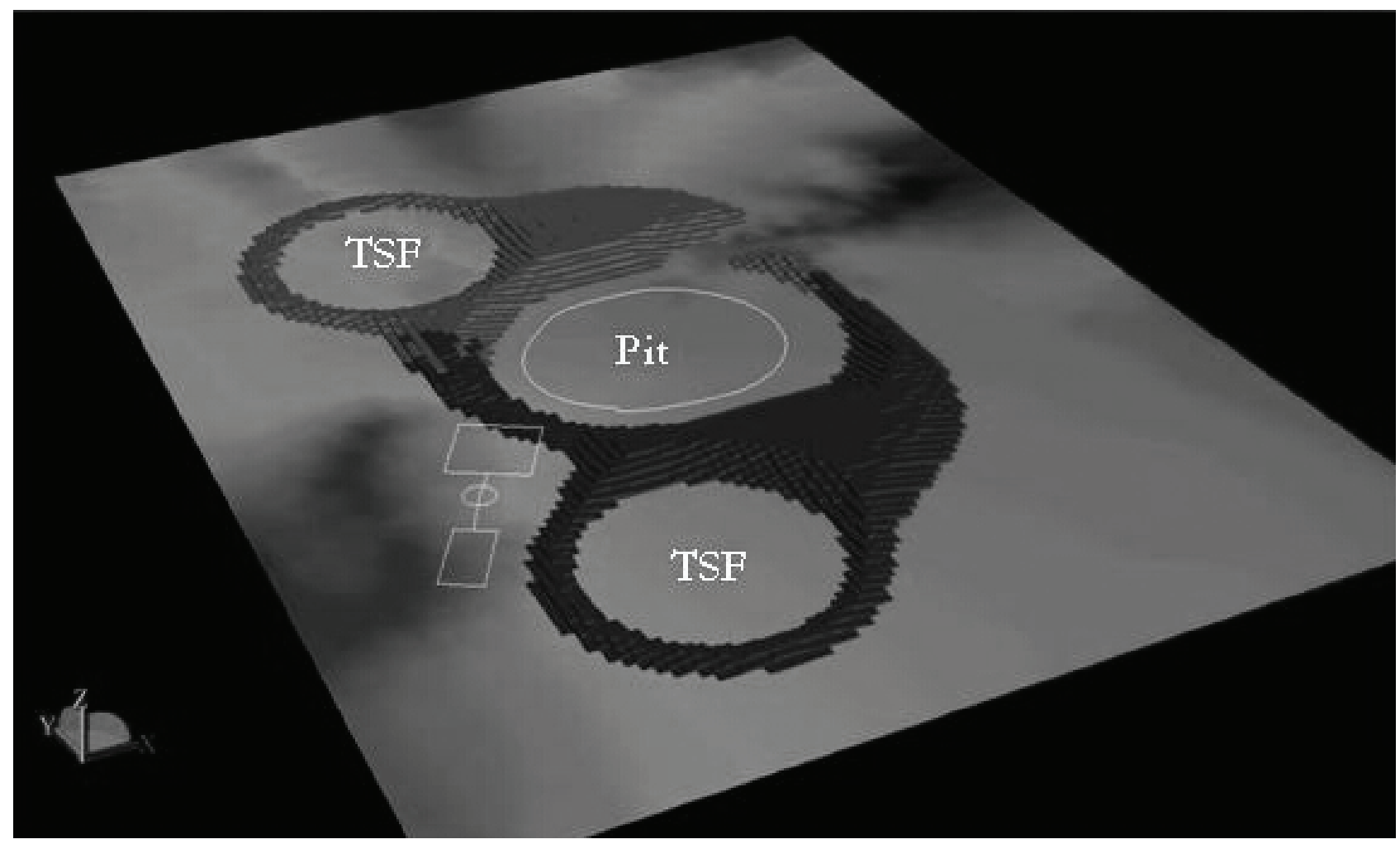

Figure 2 Integrated Waste Landform (IWL) resulting from a strategic assessment of options for tailings storage and waste rock placement, that were optimal for both operations and closure

\section{CONCLUSIONS}

Low cost and low risk landforms can be achieved if the correct planning is undertaken. They are not mutually exclusive. For this to take place there needs to be recognition by management that a multi disciplinary approach is required.

A scientific understanding of the physical and chemical properties of waste materials via appropriate characterisation is essential. The development of simple, site specific tests, to ensure that all waste can be classified in the field is an important aspect of material characterisation and associated planning.

The development of a landform construction plans that follow a regularly reviewed Dumping Plan, formal risk assessments and periodic reviews of the waste landform will ensure that the required outcomes are achieved, optimising costs and environmental issues, and significantly reducing the requirements for costly remediation and repair at closure.

\section{ACKNOWLEDGEMENTS}

The authors would like to acknowledge BHP Billiton Ltd - Nickel West and Oxiana Ltd for the landform examples included within this paper.

\section{REFERENCES}

Campbell, G. (2004) Store/Release Covers in the Australian Outback: A Review. In: Mine closure - Towards Sustainable Outcomes. Australian Centre for Geomechanics, Perth, August 2004.

Cerdà, A. (2001) Effects of rock fragment cover on soil infiltration, interrill runoff and erosion. European Journal of Soil Science, 52, pp. $59-68$. 
DITR (2006) Mine Rehabilitation Booklet - Leading practice sustainable development program for the mining industry. Stakeholder consultation draft. Department of Industry, Tourism and Resources. Canberra, Australia.

DoIR (1996) Guidelines for Mining in Arid Environments. W.A. Department of Industry and Resources, Perth Western Australia.

Dowd, P. (2005) The Business Case for Prevention of Acid Drainage. The International Network for Acid Prevention (INAP) conference. Keynote speech 23 August 2005.

Figueiredo, T. and Poesen, J. (1998) Effects of surface rock fragment characteristics on interrill runoff and erosion of a silty loam. Soil and Tillage Research, 46, pp. $81-95$.

Jasper, D.A. and Braimbridge, M. (2006) Waste characterisation for optimal landforms. In: Proceedings Goldfield Environmental Management Group 2006 Workshop. G.E.M.G. Kalgoorlie.

Jones, H. (2004) Landform evolution. In: 'Mine Closure - Towards sustainable outcomes'. Australian Centre for Geomechanics, Perth, W.A., 5-6 August 2004.

Lane, J.C. (2004) Integrated landforms - an alternative approach to tailings storage. In: 'Mine Closure- Towards sustainable outcomes’. Australian Centre for Geomechanics, Perth, W.A., 5-6 August 2004.

Lottermoser, B.G., Ashley, P.M. and Lawie, D. C. (1999) Environmental geochemistry of the Gulf Creek copper mine area, north-east New South Wales, Australia. Environmental Geology, 39(1), pp. 61 - 74.

Mamedov, A.I., Levy G.J. Shainberg, I. and Letey, J. (2000) Wetting rate, sodicity, and soil texture effects on infiltration rate and runoff. Australian Journal of Soil Research, 39, pp. 1293 - 1305.

May, G. (2004) Woodcutters Closure. In: 'Mine Closure - Towards sustainable outcomes'. Australian Centre for Geomechanics, Perth, W.A., 5-6 August 2004.

Merrill, S.D., Ries, R.E. and Power, J.F. (1998) Subsoil Characteristics and Landscape Position Affect Productivity of Reconstructed Mine Soils. Soil Science Society of America Journal, 62, pp. $263-271$.

Murphy, B.W. and Flewin, T.C. (1993) Rill erosion on a structurally degraded sandy loam surface soil. Australian Journal of Soil Research, 31(4), pp. $419-436$.

O’Kane, M., Porterfield, D. and Weir, A. (1999) Pyritic shale integration into waste rock management, Mt Whaleback. In: National Meeting of the American Society for Surface Mining and Reclamation, Scottsdale, Arizona.

Roberts, J.A., Daniels, W.L., Bell, J.C. and Burger, J.A (1988) Early stages of mine soil genesis in a southwest Virginia spoil lithosequence. Soil Science Society of America Journal, 52(3), pp. 716 - 723.

Russell, M. and Jasper, D.A. (2004) Landform Solutions - Planning for Closure. In: Mine closure - Towards Sustainable Outcomes. Australian Centre for Geomechanics, Perth, August 2004.

Shainberg, I., Warrington, D. and Laflen, J.M. (1992) Soil Dispersibility, Rain Properties, and Slope Interaction in Rill Formation and Erosion. Soil Science Society of America Journal, 56, pp. 278 - 283.

Sheridan, G.J., So, H.B., Loch, R.J., Pocknee, C. and Walker, C.M. (2000) Use of laboratory-scale rill and interill erodibility measurements for the prediction of hillslope-scale erosion on rehabilitated coal mine soils and overburdens. Australian Journal of Soil Research, 38(2), pp. 285 - 298. 